\title{
O PAPEL DO ESTADO SOBRE O DOMÍNIO ECONÔMICO POR MEIO DE FOMENTOS
}

\author{
THE ROLE OF THE STATE ABOUT THE ECONOMIC \\ DOMAIN THROUGH INCENTIVE
}

\begin{abstract}
RESUMO: O presente artigo foi impulsionado pela importância da intervenção do Estado sobre o domínio econômico por meio de fomentos. Estes incentivos, previstos constitucionalmente visam equilibrar a economia em regiões pouco desenvolvidas. Todavia, diante da ma utilização da política de beneficiamento promovida pelos governos estaduais quando se trata de isenção fiscal gerada por essa política fomentadora, acaba por gerar a guerra fiscal entre os estados. A própria Constituição Federal ao prever essa intervenção se baseia no interessa da justiça social. No entanto, os Estados ao agirem por meio do ICMS, o qual é de sua competência legislar sobre isenção ou não, pode vir a quebrar o pacto federativo. Dessa forma, procura-se por meio de órgãos como o CONFAZ, a Autarquia CADE, regularizar essa política sem deixar que se fira o principio da livre concorrência. Assim, pelo principio da proporcionalidade espera-se que a intervenção do Estado seja na forma de equilíbrio entre produção e consumo, fazendo com que o fomento seja utilizado na função constitucional, ou seja desenvolvimento do interesse coletivo.
\end{abstract}

Josyane Mansano ${ }^{1}$

Palavras-chave: Intervenção; Fomento; Guerra fiscal.

\begin{abstract}
This article was driven by the importance of State intervention on the economic domain through tax incentives. These incentives, provided for constitutionally aim to balance the economy in underdeveloped regions. However, given the ma use processing policy promoted by Governments when it comes to tax exemption generated by this policy promotion, ultimately generating fiscal war between the States. The Federal Constitution to provide for such intervention is based on matters of social justice. However, the Member States to act through ICMS, which is its competence to legislate on exemption or not, could break the federative pact. This way, through bodies such as the CONFAZ, CADE, regulatory this policy without letting yourself the principle of free competition. Thus, by the principle of proportionality, it is expected that State intervention is in the form of balance between production and consumption, causing the promotion is used in constitutional role, and development of collective interest.
\end{abstract}

Palavras-chave: Intervention; Tax Incentive; Tax War.

\footnotetext{
1 MANSANO, Josyane. Especialista em Direito Civil e Processo Civil pelo Instituto Paranaense de Ensino em Maringá - PR, Mestranda em Direito Empresarial pela UNIMAR - SP. Advogada em Maringá. Endereço eletrônico: Jo271002@hotmail.com.
} 


\section{NTRODUÇÃO}

Quando o Estado, a disposição do que diz a Constituição Federal faz o papel de intervenção na economia, ela o faz por meio de incentivos fiscais, com o objetivo de maximizar o desenvolvimento de lugares pouco desenvolvidos visando o equilíbrio, conforme prevê o Art. 23 da CF/88.

Entretanto, ao tentar se utilizar do sistema de freios e contrapesos, o Estado acaba passa a ter influencia no preço final da mercadoria, fazendo com que a curva da oferta seja deslocada para baixo (diferente do que ocorre com quem não tem o incentivo). Isso porque o fomento acaba influenciando no preço final da mercadoria.

Essa intervenção na economia pode ser dar por meio de incentivos fiscais, e no âmbito estadual, isso é aplicado principalmente no que tange ao ISCM. A própria Constituição Federal ao elencar esse dever para o Estado, passa a descentralizar essa competência para os mesmo, e estes por sua vez fazem mau uso dessas políticas públicas de beneficiamento promovida pelo governo.

Por ser advindo de um processo legislativo de maioria simples para sua votação, a saber, por meio de lei ordinária, a isenção do ICMS, passa a ter valores que ultrapassam a imaginação do legislador, com o intuito de atrair mais investimentos e mercado para o seu estado.

O resultado disso é uma disputa entre os entes federados, ocasionando a chamada guerra fiscal.

No entanto, é de se ressaltar que a própria Constituição Federal é capitalista em seu teor, e que para não quebrar o pacto federativo, necessário se faz um federalismo de cooperação para essa política de incentivo.

O que se espera, no entanto, é que a União ao atribuir estas competências aos Estados, também cumpra seu papel, conforme dispõe no Artigo 174 da CF, ou seja, o de regulamentar, fiscalizar e planejar o desenvolvimento econômico, sempre respeitado o principio fundamental da isonomia.

O poder normativo vem nesse âmbito com a Lei de Responsabilidade Fiscal e o Conselho Fazendário (CONFAZ), fiscalizar essa intervenção no domínio econômico por meio de fomentos, assim como faz a Autarquia Federal CADE. Tudo isso para fazer com que não haja privilégios gerados pela guerra fiscal a partir do ICMS, onde os Estados mais desenvolvidos da Federação obtém vantagens para instalação de empresas por exemplo.

Nesse estudo primeiramente se falara sobre a ordem econômica prevista na Constituição Federal, as formas de controle do Estado quando se trata de livre concorrência e livre iniciativa, o fomento na economia atuando sob os tributos por meio da isenção, a competência dos estados em relação ao ICMS, a guerra fiscal e a Lei de Responsabilidade Fiscal. 


\section{A ORDEM ECONÔMICA PREVISTA NA CONSTITUIÇÃO FEDERAL}

A intervenção no domínio econômico prevista na Constituição Federal, em seu Artigo 174, dispõe que:

Art. 174. Como agente normativo e regulador da atividade econômica, o Estado exercerá, na forma da lei, as funções de fiscalização, incentivo e planejamento, sendo este determinante para o setor público e indicativo para o setor privado.

Dessa forma, imperioso destacar que o Estado passa a agir nas atribuições de agente, impondo regras e condições, para assim fluir a economia nacional.

O magistério de SALOMÃO FILHO (2001, 99. 30-35), assim ensina:

O Estado impõe regras e condições por meio da denominada "função de polícia”, para a realização de determinada atividade econômica, de forma a manter o equilíbrio econômico, preservar a livre iniciativa e concorrência, e ainda proteger o consumidor de eventuais danos causados pela conduta das empresas atuantes no mercado.

Quanto a relatar os incentivos a que se refere o artigo constitucional, tem-se que estes servem para determinados setores da economia, visando o aumento das externalidades positivas, dessa forma, a intervenção ora estudada, quando objetivando incentivo, se dá na forma de fomento.

Estes fomentos, podem ocorrer de várias formas, como por meio de benefícios fiscais, empréstimos e subsídios, em acordo com o Art. 174 da Constituição.

Isso porque eles não podem se dar de forma desordenada, não se pode ferir fundamentos constitucionais, tais como a o principio da isonomia, BORGES (1994, p. 91), assim elenca: “ A legalidade assume, na Constituição Federal de 1988 um papel eminentíssimo. Até porque somos governados por uma legalidade isonomia (CF, art. $5^{\circ}$, caput I e II): “ Todos são iguais perante a lei"."

Nos exatos termos da CF/88, a União poderá utilizar-se de contribuições interventivas como instrumento de sua atuação no domínio econômico. Tal exação, assim, servirá como instrumento para a União intervir no domínio econômico.

De acordo com GRAU (2003, p. 126), nesse ponto, elenca que:

Oesforçoparase definira expressão “domínio econômico"restaatenuado, vezque, aidéia central refletida pela Constituição é a de que se trataria do loco reservado à atuação dos agentes econômicos privados, no exercício da atividade econômica em sentido estrito. 
Com esse substrato constitucional, a Doutrina de PIMENTA (2002, p.38-40) discriminou essa intervenção do Estado em duas formas, a saber, direta e indireta.

\begin{abstract}
Pela primeira, o Estado intervém no domínio econômico, como verdadeiro agente, assumindo integralmente (por absorção) ou parcialmente (por participação) o controle dos meios de produção e/ou troca de determinado setor da atividade econômica em sentido estrito. Ou seja, o Estado, através de um ente com personalidade jurídica própria (empresa pública, sociedade de economia mista ou subsidiária), atua no domínio econômico, seja sob o regime de monopólio, seja em concorrência com os demais agentes econômicos da iniciativa privada.
\end{abstract}

Assim, o Estado ao intervir de forma indireta se limita a condicionar a atividade econômica, e acaba exercendo a função normativa e regulatória, como enuncia a Constituição de 88 . Assim, o Estado acaba exercendo uma pressão sobre a economia, estabelecendo mecanismos e normas. Portanto, diante da posição adotada por ele, cabe escolher qual o caminho mais favorável a ser tomado, para gozar de melhores condições para o exercício da atividade econômica.

Em relação à intervenção, GRAU (2003, p. 127), entende que: “O Estado intervém não mais no domínio econômico, porém sobre ele.”

Dessa forma a Constituição não limita o exercício da função regulatória pelo Estado à adoção de medidas de caráter positivo. Ao contrário, a Constituição se preocupou em gizar que uma intervenção estatal apontando para a consecução dos objetivos elegidos nela como finalidades que espelhem os princípios da ordem econômica, seja através de uma ação negativa, seja através de uma ação positiva.

A adoção, pelo Estado, de políticas econômicas e medidas administrativas ou legislativas no âmbito econômico deverá, sim, levar em conta os fundamentos e os princípios norteadores da ordem econômica explicitados no art. 170, a saber:

Art. 170. A ordem econômica, fundada na valorização do trabalho humano e na livre iniciativa, tem por fim assegurar a todos existência digna, conforme os ditames da justiça social, observados os seguintes princípios:

I - soberania nacional;

II - propriedade privada;

III - função social da propriedade;

IV - livre concorrência;

Assim, se uma intervenção no domínio econômico for necessária, é de bom alvitre considerar que, é importante passar pelo crivo do princípio da proporcionalidade, em seus três 
aspectos (adequação, necessidade e proporcionalidade), instrumento essencial ao Estado Democrático de Direito e garantidor da efetivação dos bens jurídicos constitucionalmente tutelados e da proibição do excesso das medidas estatais.

O princípio da proporcionalidade ou princípio da razoabilidade, serve nessa óptica para analisar a inconstitucionalidade da violação a outro principio muito importante no ordenamento jurídico, que é o da livre concorrência. Assim, a regra da razão, como é conhecida, prevê o equilíbrio entre produção e consumo, e equilibra a razoabilidade do mercado quando há conflito entre o principio da livre concorrência e ações de fomento.

\section{FORMAS DE CONTROLE DO PRINCÍPIO DA CONCORRÊNCIA}

O Poder Legislativo cria as leis que devem regular as relações econômicas, cabendo ao Poder Executivo sua regulamentação, implementação e fiscalização (Política de controle), com um limite de intervenção mínima, evitando-se com isso conflitos entre o comportamento do mercado, sempre no sentido de preservar o direito de propriedade, a livre iniciativa e a atividade econômica.

A livre iniciativa e a livre concorrência é pilastra mestre da atividade econômica, vez que a diversidade e competitividade de ofertas proporcionam progresso econômico e social em benefícios dos cidadãos, por isso o Estado tem que exercer o seu papel constitucional de mão forte na preservação da ordem econômica, por força do $\S 4^{\circ}$., do art. $173 \mathrm{c} / \mathrm{c}$ o art. 170, IV, da C.F/88.

Para tanto, diversos são os meios e instrumentos que o Estado pode lançar mão para a condução da sua política econômica, destacando-se entre elas os fomentos que também podem ser chamados de estímulos à preservação e continuidade da atividade econômica.

O Poder Executivo, detentor das atribuições como regulamentador e fiscalizador das práticas das atividades econômicas e os abusos cometidos pelo mercado, tem a sua disposição o Conselho Administrativo de Defesa Econômica - CADE, que apesar de estar subordinado ao Executivo, suas ações são eminentemente técnicas e desvinculadas de ingerência políticopartidária, conforme dispõe a Lei n. 8.884/94 (Lei Antitruste). O CADE é órgão administrativo judicante, máximo de defesa da concorrência.

Dispõe ainda do Conselho de Política Fazendária - CONFAZ, que também atua na fiscalização e regulamentação das normas de direito econômico. 


\section{Conselho administrativo de desenvolvimento econômico (CADE)}

O CADE possui jurisdição administrativa em todo território nacional, trata-se de administrativa e não judicial porque o CADE integra o Poder Executivo Federal, mesmo tendo uma função judicante não exerce nenhum poder jurisdicional, pois este é privativo dos órgãos do poder judiciário.

Ainda, cabe ressaltar que sempre que o CADE e a SDE (secretaria de desenvolvimento econômico), forem solicitados a opinarem sobre qualquer ato, que, de qualquer forma, possa prejudicar a livre concorrência ou que resulte na dominação de mercados relevantes de bens ou serviços, nos termos da legislação vigente, os interessados deverão respeitar e implementar as regras impostas pela autarquia, no sentido de cumprirem as condições estabelecidas por esta e pela própria SDE, através do compromisso de desempenho.

Das decisões que sobrevierem desses órgãos, com imposições de sanções administrativas ou pela inobservância de suas diretrizes, tendo em vista o Poder de Polícia do Estado, cabe invocar a apreciação do Poder Judiciário, para obtenção de decisão, através dos meios jurídicos competentes.

A atuação da Autarquia pode ser feita pelo controle da conduta, que vem delinear regras de comportamento para os componentes participantes do mercado. A finalidade principal é inibir, proibir e sancionar comportamentos indesejáveis de condutas desses agentes econômicos, tais como formação de cartel, venda casada, acordos de exclusividade, entre outros.

O controle pode ser realizado também na estrutura do mercado, ou seja, por meio de controle de contratos de fusão, incorporação, aquisição, todas as formas de atrair a concentração econômica para um pequeno grupo, concentrando poder, dificultando a concorrência e que agem manipulando o mercado.

Já foi visto anteriormente que no Brasil a CF ao dispor sobre a exploração das atividades econômicas, fundamenta a ordem econômica na valorização do trabalho humano e no principio da livre iniciativa.

O que ocorre é que há certa margem de liberdade para os blocos econômicos agirem, para assim continuarem fomentando as atividades econômicas, o trabalho humano, a movimentação da balança comercial, e tudo mais. Isso faz com que haja desequilíbrios para com esses gestores econômicos, é ai que entra a Autarquia Federal, o CADE, para colocar ordem nessas negociações.

Face a essa predominante atuação do CADE, que se justifica por essa atual política econômica desenvolvida no pais, fundada nessa abertura econômica que expôs o Brasil a con- 
corrência internacional, COELHO (1999, p.233), traz o seguinte apontamento sobre a Autarquia: "Atualmente o CADE tem-se dedicado muito mais a apreciação dos atos de concentração do que do que ao julgamento dos processos administrativos sobre condutas infracionais."

Para SOTERO (2008, p.73), a competência desta Autarquia quanto ao processo administrativo por ela instaurado quando verificada violação a ordem econômica, é assim entendida;

\begin{abstract}
A competência exclusiva do CADE na tutela Administrativa é de competência exclusiva do conselho administrativo de defesa econômica - CADE e não ao poder judiciário apreciar e julgar as infrações administrativas contra a ordem econômica, desse modo não cabe ao poder judiciário aplicar as sanções administrativas previstas nos artigos 23 e 24 da lei n. 8.884/94. Tal atribuição é exclusiva do CADE, quando do julgamento de processo administrativo instaurado para o fim de apuração de infração administrativa contra a ordem econômica.
\end{abstract}

Finalmente, destaca-se que a lei 8884/94, que dispõe sobre o CADE, deve ser interpretada em conformidade de tal forma que ela seja importante no meio da concretização dos objetivos da República e da ordem econômica. Essa lei obedece às peculiaridades de fato tal como se lhe apresenta no tempo, no espaço e no caso concreto.

\title{
FOMENTO NA FORMA DE ISENÇÃO TRIBUTÁRIA
}

Com escopo de situar no tempo a temática da isenção e da imunidade tributária, primeiramente vale a pena conferir o que o Código Tributário Nacional, tem a dizer sobre a isenção:

Art: 176 do CTN: “A isenção, ainda quando prevista em contrato, é sempre decorrente de lei que especifique as condições e requisitos exigidos para a sua concessão, os tributos a que se aplica e, sendo caso, o prazo de sua duração."

Parágrafo único. A isenção pode ser restrita a determinada região do território da entidade tributante, em função de condições a ela peculiares.

Sobre a temática, BORGES (1994, p. 95) assim leciona:

Quando a Constituição Federal da uma competência material, não necessariamente permite seja ela exercitada por qualquer forma. Os estados - membros podem instituir incentivos fiscais do ICMS (CF, art. 151, I, in fine). Não lhe incumbe porem concedelo unilateralmente. E esses incentivos fiscais podem consistir em isenções, reduções, concessão de credito presumido do ICMS etc. um mundo de formas atípicas, cujo limite é a imaginação, e que acarretam a exoneração do ICMS. 
Desta feita, tem-se na mais apertada síntese que isenção significa o favor fiscal, instituído em lei, consistente na dispensa do pagamento do tributo devido. Portanto, na sua percepção, a dinâmica do fenômeno isentivo seria: ocorrência do fato gerador, incidência tributária, nascimento da obrigação e dispensa do pagamento do tributo devido. Dessa forma, busca-se por meio da principiologia da ordem econômica nacional previsto constitucionalmente alavancar o desenvolvimento nacional.

A seguinte passagem ratifica o quanto se afirmou, segundo NAVARRO (1994, p. 393): "Na isenção o tributo é devido, porque existe a obrigação, mas a lei dispensa o seu pagamento; por onseguinte, a isenção pressupõe a incidência."

Outros juristas de escola perfilharam igual posicionamento. Em apertada síntese, MORAES, citado por NAVARRO (1994, p. 393), aponta:

\begin{abstract}
A isenção tributária consiste num favor concedido por lei no sentido de dispensar o contribuinte do pagamento do imposto. Há concretização do fato gerador do tributo sendo este devido, mas a lei dispensa seu pagamento.
\end{abstract}

Segundo BECKER (1998, p. 304), a respeito do elemento faltante ou excedente é que irá entrar na composição do suporte fático da regra isentiva, diz: "A regra jurídica da isenção incide para que a de tributação não possa incidir."

O mesmo autor ainda preleciona, (1998, p. 95) em parecer publicado pela Revista Trimestral de Direito Público:

Incentivos fiscais não escapam ao regime constitucional. Porque não tem hodiernamente caráter de "favor", soa "benéficos" e porque não instituem "privilégios", são "incentivos" legitimados constitucionalmente.

Segundo BORGES (1969, p. 189-190):

A norma que isenta é, assim, uma limitadora ou modificadora: restringe o alcance das normas jurídicas de tributação; delimita o âmbito material ou pessoal a que deverá estender-se o tributo ou altera a estrutura do próprio pressuposto da sua incidência.

Importa ainda reter as conclusões a que o autor chega em face do confronto entre os institutos da isenção e da imunidade. Para ele, a distinção está em que: 
poder tributante do ente, enquanto a isenção opera a retirada do ato, bem ou pessoa do suporte da norma instituidora do tributo. Assim, na imunidade, o ente não tem poder para tributar, na isenção, por decisão legislativa infraconstitucional, não ocorre a tributação de fatos que, em face da competência tributária, poderiam integrar a compostura da hipótese de incidência da norma tributante.

No esforço de bem compreender o tema, surge o ensejo de trazer à baila o pensamento de CARVALHO (1998, p. 331):

Conclui que as isenções tributárias são espécies de normas de estrutura. Lançando mão da sua proposição descritiva da regra-matriz de incidência, na qual visualiza dois segmentos: a hipótese ou descritor, integrada pelos critérios material (verbo mais complemento), espacial e temporal, e a conseqüência ou prescritor, formada pelos critérios pessoal e quantitativo (base de cálculo mais alíquota), sustenta que a regra de isenção investe contra um ou mais dos critérios da norma-padrão de incidência, mutilando-os, parcialmente.

Resta portanto ressaltar, que mesma a isenção atuando como forma de fomentar a economia vigente, há necessidade de se ter certa cautela para com o uso indiscriminado, para assim não se deparar com situações que possam ferir o princípio da isonomia, que possam a vir causar danos aos Estados membros.

\section{A isenção do tributo do ICMS (imposto estadual que tributa a circulação de mercadorias e alguns serviços)}

Entende-se por Estado Federal o próprio governo central. É da União a centralização das decisões em detrimento da autonomia dos demais membros. O Estado federal é a representação máxima de um Estado que é montado em cima do federalismo.

Em algumas matérias, é exclusividade do Estado Federal legislar. Exemplo disso é questão de matéria tributária, porém, a $\mathrm{CF} / 88$ deu atribuições aos Estados e aos municípios de legislarem sobre alguns impostos. Neste caso importa apenas os impostos de competência estadual. Dispõe o texto constitucional em seu artigo 155:

Art. 155 CF:Compete aos Estados e ao Distrito Federal instituir impostos sobre:

"II - operações relativas à circulação de mercadorias e sobre prestações de serviços de transporte interestadual e intermunicipal e de comunicação, ainda que as operações e as prestações se iniciem no exterior;" 
Da leitura do texto constitucional pode-se averiguar que, a Constituição atribuiu aos Estados estabelecer leis concernentes ao Imposto sobre Circulação de Mercadorias e Serviços.

Hoje os estados tem total autonomia legislativa em relação ao ICMS. Por isso, no Brasil são cerca de 27 legislações estaduais sobre o ICMS. Cada Estado tem a sua, com diferentes alíquotas para os mais diversos tipos de produtos.

Todavia, não se pode deixar de levar em conta que, a autonomia dada pela União aos Estados deve ser precedida de responsabilidade e limites.

Decorrente dessa política descentralizada, da União para os Estados, em relação ao ICMS, que ao almejar maior desenvolvimento regional, certos Estados acabam por atropelar essa competência, de forma a para atrair investimentos para a sua região fomentar por meio de impostos incentivos para empresas. Esse fomento gera a chamada guerra fiscal, tópico que será estudado mais adiante em capitulo próprio. Destarte, tem-se aí a mazela que trás esse tipo de competência ser dada aos Estados.

Em Dissertação de Mestrado apresentada ao Instituto de Economia da Universidade Estadual de Campinas, ALVES (2001, p. 47), ao defender o tema "Guerra fiscal e finanças federativas no Brasil: o caso do setor automotivo", assim elucida:

Do ponto de vista nacional, a guerra fiscal implica em desperdício de recursos, pois se abre mão de receita fiscal para assegurar a instalação de um investimento que certamente ocorreria no país, onde seria isso independente do incentivo fiscal.

Ainda conclui que: "a perda de arrecadação decorrente do subsídio embutido no deferimento do ICMS não incide sobre o estado, mas sim sobre o país como um todo (e evidentemente, sobre o estado apenas enquanto parte do país)."

Assim, o maior prejudicado dessa descentralização da competência tributária passa ser a União, que de alguma forma terá que substituir esse rendimento que deixou de entrar no orçamento.

\section{A guerra fiscal como conseqüência da isenção tributária do ICMS}

A guerra fiscal, com já visto, é resultado da disputa entre os estados em conceder incentivos fiscais para atrair investimentos. Esses incentivos são dados no âmbito do ICMS. Esta prática se dá via concessões de benefícios fiscais, financeiros e de infra-estrutura para as empresas interessadas em investir ou transferir seus investimentos para o estado concessor do benefício. 
Os incentivos fiscais são dados pelo estado através de renúncia parcial ou total, do ICMS, único imposto para a isenção. Após o período ditatorial, onde houve uma centralização na tributação nacional, o Brasil experimenta um regime democrático onde se prima pela descentralização das políticas públicas, e por conseguinte, das políticas tributárias. Essa autonomia trouxe aos governadores amplas vantagens, de sozinhos brigarem por investimentos que, na ânsia de quererem tirar seus estados do subdesenvolvimento, acabam fazendo qualquer negócio para atrair investimentos, mesmo que prejudique a União.

Em parecer sobre a guerra fiscal ocasionada pela isenção de tributos, BORGES (1994, p. 91), destaca que: “Antes porém um lembrete: o direito ao abatimento do ICMS tem como contrapartida o dever de fiscalizar as operações tributáveis."

A guerra fiscal não é uma disputa saudável. Ela se trava à revelia do Conselho Nacional de Política Fazendária - CONFAZ, como já estudado.

Segundo PRADO e CAVALCANTI (1998, p. 42): "a maior parte das decisões de investimento envolvidas na guerra fiscal inpedem, em grande medida, a oferta de incentivos."

Com a promulgação da Constituição de 1988, consagra-se êxito a esse grupo formado principalmente por prefeitos e governadores.

Essa Guerra estimula a disputa entre estados que objetivam a promoção do desenvolvimento regional e utilizaram a concessão de benefícios às empresas para a instalação de novas plantas industriais no seu território. Ela é ponto de vista federativo de uma competição não-cooperativa que afeta a federação, pois não segue os critérios estabelecidos na lei complementar $n^{\circ} 24$ de 1975 que pró́be os estados de concederem incentivos fiscais sem a aprovação do CONFAZ. Com isso a federação perde, pois não são levados em conta os aspectos futuros da prática não-cooperativa, levando os estados a aumentarem ainda mais as desigualdades econômico-sociais.

Em alguns casos não há apenas a intenção de incentivar a entrada de novos investimentos para a região, mas estimular a "pirataria fiscal" como define Clovis Panzarini, citado por SAPIENZA (1998, p 41).

Enquanto um Estado se beneficia, gera algum prejuízo para outro, evidenciando assim que a guerra fiscal é extremamente nociva ao equilíbrio federativo. 


\section{Casos práticos de incentivo do ICMS}

Quando a Mercedes-Benz anunciou a sua intenção de investir no Brasil, as duas locações preferenciais apontadas por ela eram a própria cidade de Juiz de Fora, em Minas Gerais e a cidade de Joinville, em Santa Catarina, restou instalada no Estado mineiro.

Os principais incentivos estão colocados abaixo, bem como os cálculos relativos ao subsídio envolvido em cada operação.

$\begin{array}{ll}\text { Benefício Orçamentário }(\mathrm{R} \$) & \\ \text { Terreno } & 50.500 .000,00 \\ \text { Crédito para Capital Fixo e de Giro } & 60.636 .705,00 \\ \text { Infra-estrutura } & 0,00 \\ \text { Crédito para Capital Fixo } & 7.117 .810,00 \\ \text { Crédito à Comercialização } & 16.757 .790,00 \\ \text { Total } & 135.012 .305,00 \\ & \\ \text { Credito para Capital de Giro (diferimento) } & 555.535 .435,00 \\ \text { Total } & 55.535 .435,00 \\ & \\ \text { Total Geral } & 690.547 .740,00\end{array}$

Fonte: Alvez (2001, p. 67)

Esse total geral, éo valor que foi dado de incentivo tributáriopara a instalação desse empreendimento no estado mineiro e não no estado catarinense, a questão é levantar quem paga a conta de tamanha ajuda? Pois para ganhar essa chamada "concorrência" algum Estado fomentou mais que o outro, desta feita conclui-se houve maior diminuição de receita para aquele que mais deu incentivo.

Já o caso entre a General Motors (GM) e o governo do Rio Grande do Sul, começou quando o governo gaúcho enviou à Assembléia Legislativa, projeto de lei definindo os benefícios negociados para a instalação da GM no estado. São Paulo havia se interessado também pelo projeto, mas o estado gaúcho saiu na frente a partir dessa iniciativa legislativa. Este projeto de lei incluía alterações nas regras do FUNDOPEM e a criação de um fundo especial para o financiamento do ICMS a ser pago pela montadora e seus fornecedores, o FOMENTAR . 
O Estado gaucho deixou um período de amortização de 30 anos para este empreendimento, o estado ainda se comprometeu a restituir o equivalente em dólares da totalidade do investimento realizado em ativos fixos. Esta restituição dar-se-ia mensalmente, em valor equivalente a 5,5\% do faturamento bruto mensal, a ser abatido diretamente do ICMS devido pela GM.

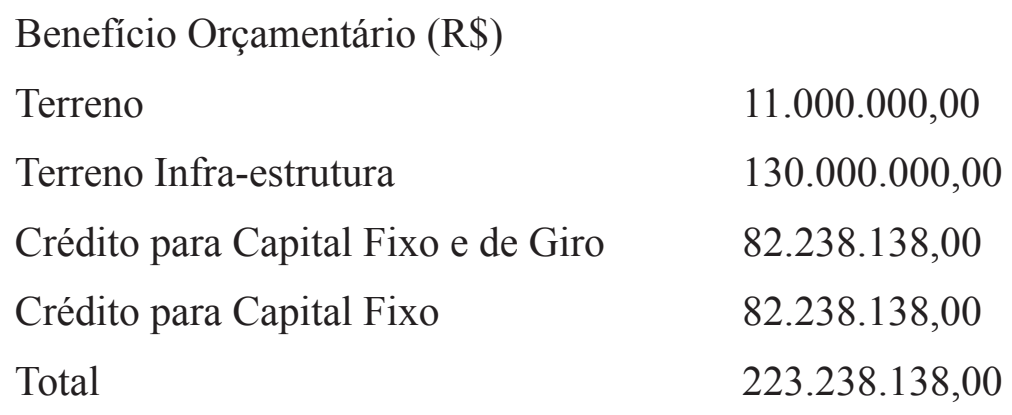

Benefício Tributário $(\mathrm{R} \$)$

Credito para Capital de Giro (diferimento) 451.244.379,00

Financiamento à aquisição de máq. e equip.15.904.166,00

Restituição do Investimento $\quad 69.190 .001,00$

Total

$536.338 .546,00$

Total Geral

$759.576 .684,00$

Fonte: Alves (2001, p.75)

Por óbvio, se verifica nos montantes, a exemplo destes dois casos, os valores que o Estado deixa de arrecadar, por meio desse incentivo tributário. Inicialmente, atrair estes tipos de investimentos para determinada região, nem de longe é um mal negócio, todavia, o que se pretende é de certa forma não deixar o vazio orçamentário, para não dizer "rombo", nas contas públicas, tendo a União que arcar com isso, tirando investimentos, muitas vezes que já tinham outro destino.

Fomentar a economia como forma de atrair bons investimentos não deixa de ser uma política pública plausível, o que ocorre no entanto é que para um Estado membro atrair a menina dos olhos de empresas como estas, muitas vezes passa por cima de margens econômicas que já se encontram equilibradas, para abrir um incentivo, que nem sempre vai trazer no futuro bom 
retorno ao membro da federação, até porque se o empreendimento não dá certo, a empresa tem um período muito longo para amortização, coisa na casa de 30 anos.

\section{O VERDADEIRO OBJETIVO DA ISENÇÃO TRIBUTARIA}

O ICMS, como já visto, é um imposto do tipo Imposto sobre Valor Agregado - IVA, que incide sobre mercadorias e serviços. - É importante salientar que o Brasil é o único país do mundo onde o imposto de maior arrecadação é de competência dos Estados e não da União. - Um exemplo simples pode elucidar como funciona o imposto responsável por $25 \%$ da arrecadação tributária nacional.

Tomemos como exemplo uma empresa de mineração, que extrai minério de ferro e o vende a uma fundição. O minério é tributado quando é vendido à fundição. A fundição o transforma em portas para geladeiras, e essas peças são novamente tributadas quando vendidas a uma fábrica de geladeiras. Quando a fábrica vende as geladeiras às lojas de varejo, a mercadoria é novamente tributada, e o consumidor final paga na hora da compra o tributo, onde a alíquota varia de estado para estado. É nessa lógica que os estados procuram atrair as principais fábricas para seus estados, pois delas dependem outras empresas de pequeno porte. Logo se um Estado dá incentivos fiscais a uma empresa mineradora (observando as condições de extração mineral do solo do estado incentivador), a fundição e a fábrica de geladeiras tentarão também se firmar no mesmo Estado com o intuito de diminuir os custos de produção e consolidar-se no mercado local.

O incentivo será apenas para a mineradora, porém as demais empresas "dependentes" pagarão ICMS, ou seja, a renúncia não seria tão danosa, visto que atrairia outros investimentos.

Para os autores PRADO e CAVALCANTI (1998, p. 42), existem incentivos que podem sim ser usados com a finalidade para que forma criados: "Um exemplo pode ser o caso de programas setoriais de incentivos locais de inversão, como o incentivo à industria de turismo no Nordeste."

Agindo sob essa óptica, o desenvolvimento de regiões menos desenvolvidas passa a ser o foco do poder incentivador que possui o Estado, quando intervem de forma fomentadora na economia visando o objetivo do desenvolvimento social da coletividade, não ferindo o pacto federativo, e sim fortalecendo economias frágeis para se desenvolverem. 


\section{A LEI DE RESPONSABILIDADE FISCAL NO COMBATE À GUERRA FISCAL}

A LRF, que veio à luz para combater o desperdício de dinheiro público e estabelecer uma política de gestão fiscal responsável, estabeleceu em seu art. 11 três requisitos essenciais da responsabilidade fiscal no que se refere à receita derivada, quais sejam, a instituição, a previsão e a efetiva arrecadação de todos os tributos de competência constitucional do ente da Federação.

Em perfeita harmonia com o art. 11, a LRF estabeleceu em seu art. 14:

Art. 14 LRF: A concessão ou ampliação de incentivo ou benefício de natureza tributária da qual decorra renúncia de receita deverá estar acompanhada de estimativa do impacto orçamentário-financeiro no exercício em que deva iniciar sua vigência e nos dois seguintes, atender ao disposto na lei de diretrizes orçamentárias e a pelo menos uma das seguintes condições:

I - demonstração pelo proponente de que a renúncia foi considerada na estimativa de receita da lei orçamentária, na forma do art. 12, e de que não afetará as metas de resultados fiscais previstas no anexo próprio da lei de diretrizes orçamentárias;

II - estar acompanhada de medidas de compensação, no período mencionado no caput, por meio do aumento de receita, proveniente da elevação de alíquotas, ampliação da base de cálculo, majoração ou criação de tributo ou contribuição.

$\S 1^{\circ}$ A renúncia compreende anistia, remissão, subsídio, crédito presumido, concessão de isenção em caráter não geral, alteração de alíquota ou modificação de base de cálculo que implique redução discriminada de tributos ou contribuições, e outros benefícios que correspondam a tratamento diferenciado.

Dessa forma, procura-se exigir que ao fomentar certos setores da economia, não haja em contrapartida desequilíbrio orçamentário. É necessário que haja compensação, pois ao isentar o ICMS de forma a atrair investimentos para o estado cedente, deve-se controlar o orçamento estadual para que a dilação de prazo concedido para a empresa beneficiada por exemplo não atinja receitas que seriam destinadas para outras áreas.

Segundo a lição de HARAKA (2010), tem-se que:

\footnotetext{
De um lado, temos uma isenção por tempo certo que, embora expressa em lei, resultou da negociação entre o sujeito ativo e o sujeito passivo do tributo, no pressuposto de que tal ajuste consultaria o interesse público. De outro lado, temos a disposição de ordem pública vedando o ente político de conceder essa isenção, sem prévio estudo do seu impacto orçamentário-financeiro no exercício de sua vigência e nos dois seguintes, além de atender a Lei de diretrizes Orçamentárias e da adoção de providências para compensar a perda de arrecadação com o aumento da receita por meio da majoração ou criação de tributos.
} 
Assim, necessário se faz um estudo de impacto na economia, quando o Estado decide, pelo exposto no Art. 170 da $\mathrm{CF} / 88$, incentivar o desenvolvimento econômico.

\section{CONCLUSÃO}

Desta feita para viabilizar a atividade econômica nacional, bem como buscar incentivar o desenvolvimento econômico o Estado busca por meio de fomentos atuar nesse âmbito. Essas iniciativas podem se dar por exemplo por meio de isenção tributária.

A exemplo da isenção do ICMS, imposto de competência estadual muito utilizado na forma de incentivo para atrair investimentos, o resultado muitas vezes é um certo desconforto, até porque age ferindo o principio da isonomia, por meio da guerra fiscal tributária, travada entre os estados, e que acaba por ferir o pacto federativo.

Essa guerra fiscal travada pelos estados membros, por meio dessa competência que tem os Estados em legislar sobre esse incentivo, leva a desigualar receitas e também a atrair investimentos para regiões já desenvolvidas, pois podem abrir mão dessa receita temporariamente no intuito de atrair grande pólos mercantis e industriais.

Partindo da premissa, na seara de tentar combater essa problemática trazida pela própria constituição federal ao atribuir esta competência, cabe ao poder executivo, por meio do CONFAZ, CADE, assegurar que ao intervir no desenvolvimento econômico por meio de fomentos os estados façam cumprir o direito isonômico previsto constitucionalmente.

Conclui-se, que ao Estado quando na função de fomentador da ordem econômica para tentar igualar o desenvolvimento das regiões do país, deve-se valer pelo principio da proporcionalidade, visando políticas públicas de razoabilidade do mercado para assim sem ferir o pacto federativo e o principio da isonomia dos estados, incentivar o desenvolvimento econômico visando a justiça social e o bem coletivo.

\section{REFERÊNCIAS}

ALVES, Maria Abadia da Silva. Guerra fiscal e finanças federativas no Brasil: o caso do setor automotivo. 2001. Dissertação (Mestrado em Economia) - Instituto de Economia, Universidade Estadual de Campinas, Campinas.

BASTOS, Celso Ribeiro, Ives Gandra Martins. Comentários à constituição do Brasil. São Paulo: Saraiva, 1990. v. 7. 
BASTOS, Celso Ribeiro. Curso de direito constitucional. São Paulo: Celso Bastos, 2002.

BECKER, Alfredo Augusto. Teoria geral do direito tributário. 3. ed. São Paulo: Lejus, 1998.

BORGES, José Souto Maior. Incentivos fiscais e financeiros. Revista Trimestral de Direito Público, São Paulo, n. 24, p.159-180, 1994.

BORGES, José Souto Maior. Isenções tributárias. São Paulo: Sugestões Literárias, 1969.

CARVALHO, Paulo de Barros. Curso de direito tributário. 10. ed. São Paulo: Saraiva 1998.

COELHO, Fábio Ulhoa. Curso de direito comercial. 2. ed. São Paulo, Saraiva. 2007. v. 1.

GRAU, Eros Roberto. A ordem econômica na constituição de 1988. 5. ed. São Paulo: Malheiros, 2000.

HARADA, Kiyoshi. Isenção por prazo certo e os efeitos da Lei de Responsabilidade Fiscal . Jus Navigandi, Teresina, ano 10, n. 942, 31 jan. 2006. Disponível em: <http://jus2.uol.com.br/ doutrina/texto.asp?id=7887>. Acesso em: 18 ago. 2010.

MORAES, Alexandre de. Direito constitucional. 9. ed. São Paulo: Atlas, 2001.

NAVARRO, Sacha Calmon. Comentários à constituição de 1988: sistema tributário. 6. ed. Rio de Janeiro: Forense

NERY JUNIOR, Nelson e NERY, Rosa Maria de Andrade. Constituição Federal Comentada e legislação constitucional. 2. ed. São Paulo: RT, 2009.

PIMENTA, Paulo Roberto Lyrio. Contribuições de intervenção no domínio econômico. São Paulo: Dialética, 2002.

PRADO, S. e CAVALCANTI, C. E. G. Aspectos da guerra fiscal no Brasil. São Paulo: IPEA/ FUNDAP. 1998.

SALOMÃO FILHO, Calixto. Regulação da atividade econômica: princípios e fundamentos jurídicos. São Paulo: Malheiros, 2001

SILVA, José Afonso da. Curso de direito constitucional positivo. 15. ed. São Paulo: Malheiros Editores, 1998.

TADDEI, Marcelo Gazzi. O CADE e o controle preventivo dos atos de concentração empresarial. Revista de Direito Mercantil. São Paulo, v.121, p. 95-99, 2001. 